\title{
The Efficacy of EMDR Early Interventions
}

\author{
Elan Shapiro \\ Private Practice, Ramat Yishay, Israel \\ Louise Maxfield \\ Ridgetown, Ontario, Canada
}

\begin{abstract}
This brief narrative review begins with an overview of posttraumatic response and explains the value of early treatment in reducing/eliminating symptoms of distress and possibly preventing the development of posttraumatic stress disorder (PTSD) or other disorders. The article then summarizes the efficacy of eye movement desensitization and reprocessing (EMDR) therapy as an early intervention treatment. It outlines the historical context of EMDR early interventions and describes the three protocols which have research support from randomized controlled trials (RCTs), elaborating on their supportive evidence in seven RCTs conducted within 3 months of the traumatic event. These studies showed that EMDR early interventions significantly reduced symptoms of traumatic stress and prevented any exacerbation of symptoms. EMDR was superior to wait-list and to control conditions of critical incident stress debriefing, reassurance therapy, and supportive counseling. The article also examines the disparate evaluations of EMDR early interventions in the PTSD treatment guidelines, from the International Society for Traumatic Stress Studies, the World Health Organization, and the National Institute for Health and Clinical Excellence. Despite promising clinical experience and initial controlled studies, there are still substantive gaps in the evidence base for EMDR early interventions. The article concludes with recommendations for future research, emphasizing that future trials adhere to the highest standards for clinical research and that they investigate whether EMDR early intervention prevents the development of PTSD or increases resilience.
\end{abstract}

Keywords: eye movement desensitization and reprocessing (EMDR) therapy; early psychological intervention; recent traumatic event; posttraumatic stress disorder (PTSD); treatment efficacy; guidelines

$\mathbf{W}$ hen providing eye movement desensitization and reprocessing (EMDR) therapy to recent survivors of an earthquake in California in 1989, F. Shapiro (1995) realized that an adapted protocol was necessary. Following her creation of the recent traumatic event protocol (F. Shapiro, 1995), several protocols have been developed to provide EMDR early intervention shortly after traumatic events. Research investigating the effectiveness of EMDR early intervention has shown that it significantly reduces symptoms of posttraumatic stress disorder (PTSD), with effects maintained at follow- up, showing that it prevents the exacerbation of symptoms (Maxfield, 2018).

This article presents a brief overview of the literature on early psychological intervention. It then focuses on EMDR early intervention, and summarizes the research, specifically looking at the seven randomized controlled trials (RCTs) that provided treatment within 3 months after the traumatic event. The article examines the status of EMDR early intervention in the treatment guidelines and discusses the discrepancies between the guidelines. It also makes suggestions for future research and clinical practice. 


\section{Early Intervention}

What Is the Time Frame for Early Intervention?

"Early intervention" is a term used to describe psychotherapeutic interventions that are conducted shortly after a recent traumatic incident. As a consequence of the confusion and difficulties for research continuity following the changes made in the diagnostic categories from Diagnostic and Statistical Manual of Mental Disorders, Fourth Edition (DSM-IV) to DSM-V (Yehuda et al., 2015), the guidelines differ on whether they conceptualize early intervention as being provided only during the first month, or during the first 3 months post-trauma. See Table 1. Although the time period for "early intervention" has varied slightly from one treatment guideline to another, there is "reasonable consensus in the traumatic stress field that a threemonth window is sensible as a time frame for defining an intervention seeking to prevent disorder or ameliorate early reactions / symptoms as 'early intervention"' (Dr. Neil Roberts, Personal communication, 2017). However, as noted by Dr. Roberts, "with many life changing traumas, this window is less meaningful."

The time frame for early intervention has been conceptualized within the EMDR community, by F. Shapiro's (1995) hypothesis that traumatic memories remain unconsolidated for 2-3 months posttrauma and that fragments are stored as isolated incidents, thus requiring treatment to address multiple targets. In her 2018 text, she extended the time frame for "as long as 6 months after natural and manmade disasters in locations in which conditions have not returned to normal and there has been no window of post-disaster calm/safety" (p. 225). Jarero and Artigas (2018) have expanded on the concept of "ongoing trauma," theorizing that symptoms are maintained or exacerbated when there is no posttrauma safety period with continuing retraumatization and recommended that in situations of ongoing trauma (e.g., cancer, war, refugees, natural disasters), the protocols for early intervention can be effectively applied even after some years.

A number of studies provide supportive evidence that EMDR early intervention protocols effectively reduce symptoms related to life-changing or traumatic events characterized by ongoing disruption and retraumatization (Acarturk et al., 2016; Jarero, Givaudan, \& Osorio, 2018; Saltini et al., 2017; Yurtsever et al., 2018). However, it is important to note that there is a large body of research showing that standard EMDR procedures can be used for survivors of protracted events such as war and cancer (e.g., Faretta, Borsato, Civilotti, Fernandez, \& Pagani, 2016; Hurley, 2018).

In contrast to Jarero and Artigas's (2018) prolonged memory consolidation theory is McFarlane et al.'s staging approach. Instead of problems with memory consolidation, they see a "progressive recruitment of symptoms and related biological abnormalities across time and with repeated exposures especially in emergency service personnel and military populations" (p. 3). See McFarlane, Lawrence-Wood, Van Hooff, Malhi, and Yehuda (2017) for a summary of a "substantial body of evidence" supporting their position.

\title{
TABLE 1. Early Interventions Recommended in the Treatment Guidelines
}

\author{
Within First Month \\ NICE \\ TF-CBT \\ WHO \\ Within Months 2 and 3 \\ NICE \\ TF-CBT \\ WHO \\ EMDR \\ TF-CBT \\ Stress $\mathrm{m}$ \\ Group CBT \\ Within Months 1, 2, and 3, Single Session \\ ISTSS \\ $\mathrm{EMDR}^{\mathrm{a}}$ \\ Group 512PM \\ Within Months 1, 2, and 3, Multiple Sessions \\ ISTSS \\ EMDR \\ CT $\quad$ TF-CBT \\ Note. CT = cognitive therapy; ISTSS = International Society for Traumatic Stress Studies; NICE = National Institute for Health and \\ Clinical Excellence; TF-CBT = trauma-focused cognitive behavioral therapy, or cognitive processing therapy, cognitive therapy for PTSD, \\ narrative exposure therapy, and prolonged exposure therapy; stress $\mathrm{m}=$ stress management; WHO = World Health Organization. Group \\ $512 \mathrm{PM}$ is debriefing "supplemented with cohesion training exercises" such as games requiring team cooperation (ISTSS Guidelines \\ Committee, 2018, p. 22). \\ a emerging evidence.
}




\section{The Trajectory of Posttraumatic Response}

There are wide variations in individual response to a recent critical incident. Some will have high levels of distress or unremitting symptoms; others may experience prolonged subclinical distress, impacting their quality of life with a risk of secondary complications; a substantial minority will develop debilitating psychological and/or physical disorders; and some will only have disturbances emerging much later (Bryant, Creamer, O’Donnell, Silove, \& McFarlane, 2011; Kearns, Ressler, Zatzick, \& Rothbaum, 2012; McFarlane et al., 2017; Shalev et al., 2016). However, the majority of those exposed to trauma recover spontaneously, with no clinical diagnosis. From the perspective of EMDR's adaptive information processing (AIP) model (F. Shapiro, 2018), we can say that the individual's inherent AIP system naturally and effectively processed memories of the traumatic event. Nevertheless, various studies (e.g., Morina, Wicherts, Lobbrecht, \& Priebe, 2014; Santiago et al., 2013) have reported that about $40 \%$ of those who develop PTSD do not experience spontaneous recovery.

It is also important to note that PTSD is only one of the disorders that can develop following trauma. Bryant et al. (2011) reported prevalence of the following disorders comorbidly or independently at 12 months posttrauma: PTSD 10\%, major depressive disorder $16 \%$, general anxiety disorder $11 \%$, as well as phobias and panic. In addition, there are those who may develop PTSD months or even years after the event (McFarlane et al., 2017; Utzon-Frank, Breinegaard, Bertelsen, Borritz, \& Hurwitz Eller, 2014).

\section{Early Interventions}

Early intervention tends to have three main purposes: to treat PTSD symptoms, to prevent the exacerbation of these symptoms, and to prevent the development of PTSD (and other disorders). Although there is no single treatment intervention that is currently recommended for all trauma-exposed individuals, various forms of cognitive behavioral therapy (CBT) are recommended in almost all categories. Debriefing is no longer recommended by the National Institute for Health and Clinical Excellence (NICE, 2018) and the current standard of "psychological first aid" has little systematic evidence to support it (Yehuda et al., 2015). Three treatment guidelines, which analyzed the effectiveness of early interventions for adults, included EMDR therapy in their analyses. These guidelines were published by the World Health Organization
(WHO, 2013), the UK NICE (2018), and the International Society for Traumatic Stress Studies (ISTSS, 2018). A more detailed examination of the treatment guidelines and evaluation of EMDR early interventions can be found later in this article.

\section{EMDR Early Interventions}

At least 24 published research studies have investigated the use of EMDR early intervention procedures in the treatment of posttraumatic stress, within 3 months following the traumatic episode (Maxfield, 2018). Fifteen studies were uncontrolled, three were non-randomized controlled studies, and seven were RCTs.

Two group protocols have been developed for provision of EMDR early interventions. No RCT has evaluated EMDR group treatment provided within 3 months of the traumatic event. Although there are case studies indicating that the EMDR integrated group treatment protocol (IGTP; Artigas, Jarero, Alcalá, \& López Cano, 2014; Jarero, Artigas, \& Hartung, 2006) and the EMDR group traumatic episode protocol (G-TEP; E. Shapiro, 2014) effectively reduce symptoms of traumatic stress, it is unclear how many of these studies were conducted within the 3-month early intervention window. G-TEP and EMDR-IGTPmodified for ongoing traumatic stress have been evaluated in several RCTs, which successfully utilized these group protocols beyond the 3-month period in ongoing stressful situations. Participants included cancer patients, disaster survivors, and refugees (e.g., Jarero et al., 2018; Yurtsever et al., 2018). (See Maxfield, 2018 for list of studies.)

\section{Individual EMDR Early Interventions}

The EMDR early interventions with RCT supporting evidence include three individual therapy protocols. These protocols are all characterized by a current trauma focus, with multiple target fragments.

The Recent Traumatic Event Protocol. The recent traumatic event protocol (RE, REP; F. Shapiro, 1995) focuses on the traumatic event, identifying and processing the worst part, then processing disturbing moments in chronological order and then running the "movie" to check for residual disturbance. Each disturbing moment is processed sequentially using the eight phases of the standard protocol. Evidence for REP is found in three case studies and one RCT by Tarquinio et al. (2016). See Table 2. 
TABLE 2. Randomized Controlled Trials Investigating EMDR Treatment Within 3 Months of Traumatic Event

\begin{tabular}{|c|c|c|c|c|c|c|c|}
\hline Protocol & Study & $\begin{array}{l}\text { Time } \\
\text { Since } \\
\text { Trauma }\end{array}$ & $\begin{array}{l}\text { Trauma } \\
\text { Type }\end{array}$ & $\begin{array}{l}\text { Number of } \\
\text { Sessions }\end{array}$ & $\begin{array}{l}\text { Conditions } \\
N\end{array}$ & $\begin{array}{l}\text { Comparison of } \\
\text { Symptoms at } \\
\text { Pre and Post }\end{array}$ & Comparison of Conditions \\
\hline \multirow[t]{3}{*}{ PRECI } & $\begin{array}{l}\text { Jarero, } \\
\text { Artigas, and } \\
\text { Luber } \\
(2011)\end{array}$ & $\begin{array}{l}\text { Within } \\
14 \text { days }\end{array}$ & Earthquake & $\begin{array}{l}\text { One } \\
\text { session } \\
80-130 \mathrm{~m}\end{array}$ & $\begin{array}{l}\text { Immediate } \\
N=9\end{array}$ & $\begin{array}{l}\text { Significant } \\
\text { decrease also } \\
\text { at F-Up }\end{array}$ & $\begin{array}{l}\text { Immediate }> \\
4 \text { day waiting }\end{array}$ \\
\hline & & & & & $\begin{array}{l}\text { 4-day } \\
\text { waiting } \\
N=9\end{array}$ & No change & \\
\hline & & & & & $\begin{array}{l}\text { Delayed } \\
N=9\end{array}$ & $\begin{array}{l}\text { Significant } \\
\text { decrease also } \\
\text { at F-Up }\end{array}$ & \\
\hline \multirow[t]{2}{*}{$\begin{array}{l}\text { PROP- } \\
\text { ARA }\end{array}$} & $\begin{array}{l}\text { Jarero, } \\
\text { Amaya, } \\
\text { Givaudan, } \\
\text { and Miranda } \\
(2013)\end{array}$ & $\begin{array}{l}\text { Within } 3 \\
\text { months }\end{array}$ & $\begin{array}{l}\text { Related to } \\
\text { work as first } \\
\text { responders }\end{array}$ & $\begin{array}{l}\text { Two } \\
\text { sessions } 90 \\
\mathrm{~m}\end{array}$ & $\begin{array}{l}\text { PROPARA } \\
N=19\end{array}$ & $\begin{array}{l}\text { Significant } \\
\text { decrease also } \\
\text { at F-Up }\end{array}$ & $\begin{array}{l}\text { PROPARA }>\text { Supportive } \\
\text { counseling }\end{array}$ \\
\hline & & & & & $\begin{array}{l}\text { Supportive } \\
\text { counseling } \\
N=20\end{array}$ & No change & \\
\hline \multirow[t]{3}{*}{ R-TEP } & $\begin{array}{l}\text { E. Shapiro } \\
\text { and Laub } \\
(2015)\end{array}$ & $\begin{array}{l}\text { Within } 3 \\
\text { months }\end{array}$ & $\begin{array}{l}\text { Fatal rocket } \\
\text { attack }\end{array}$ & $\begin{array}{l}\text { Two } \\
\text { sessions } 90 \\
\mathrm{~m}\end{array}$ & $\begin{array}{l}\text { Immediate } \\
N=8\end{array}$ & $\begin{array}{l}\text { Significant } \\
\text { decrease }\end{array}$ & Immediate $>1$ week waiting \\
\hline & & & & & $\begin{array}{l}1 \text { wk Wait } \\
N=9(5)\end{array}$ & No change & \\
\hline & & & & & $\begin{array}{l}\text { Delayed Tx } \\
N=7(5)\end{array}$ & $\begin{array}{l}\text { Significant } \\
\text { decrease also } \\
\text { at F-Up }\end{array}$ & \\
\hline \multirow[t]{3}{*}{ PRECI } & $\begin{array}{l}\text { Jarero, Uribe, } \\
\text { Artigas, and } \\
\text { Givaudan }\end{array}$ & $\begin{array}{l}\text { Within } \\
25 \text { days }\end{array}$ & $\begin{array}{l}\text { "Technol- } \\
\text { ogical } \\
\text { disaster" fatal } \\
\text { explosion in }\end{array}$ & $\begin{array}{l}\text { Two } \\
\text { sessions } 60 \\
\mathrm{~m}\end{array}$ & $\begin{array}{l}\text { Immediate } \\
N=13\end{array}$ & $\begin{array}{l}\text { Significant } \\
\text { decrease also } \\
\text { at F-Up }\end{array}$ & $\begin{array}{l}\text { Immediate }> \\
9 \text { day waiting }\end{array}$ \\
\hline & $(2015)$ & & workplace & & $\begin{array}{l}\text { 9-day } \\
\text { waiting } \\
N=12\end{array}$ & No change & \\
\hline & & & & & $\begin{array}{l}\text { Delayed Tx } \\
N=12\end{array}$ & $\begin{array}{l}\text { Significant } \\
\text { decrease }\end{array}$ & \\
\hline \multirow[t]{3}{*}{$\begin{array}{l}\text { EMDR- } \\
\text { RE }\end{array}$} & $\begin{array}{l}\text { Tarquinio } \\
\text { et al. (2016) }\end{array}$ & 48 hours & $\begin{array}{l}\text { Workplace } \\
\text { violence }\end{array}$ & $\begin{array}{l}\text { One } \\
\text { session } \\
90-120 \mathrm{~m}\end{array}$ & $\begin{array}{l}\text { EMDR-RE } \\
N=19\end{array}$ & $\begin{array}{l}\text { Significant } \\
\text { decrease }\end{array}$ & \\
\hline & & & & & $\begin{array}{l}\text { CISD } \\
N=23\end{array}$ & No change & EMDR-RE $>$ CISD \\
\hline & & & & & $\begin{array}{l}\text { 48-hour } \\
\text { waiting }\end{array}$ & No change & EMDR-RE $>48 \mathrm{~h}$ waiting \\
\hline
\end{tabular}

(Continued) 
TABLE 2. Randomized Controlled Trials Investigating EMDR Treatment Within 3 Months of Traumatic Event (Continued)

\begin{tabular}{|c|c|c|c|c|c|c|c|}
\hline Protocol & Study & $\begin{array}{l}\text { Time } \\
\text { Since } \\
\text { Trauma }\end{array}$ & $\begin{array}{l}\text { Trauma } \\
\text { Type }\end{array}$ & $\begin{array}{l}\text { Number of } \\
\text { Sessions }\end{array}$ & $\begin{array}{l}\text { Conditions } \\
N\end{array}$ & $\begin{array}{l}\text { Comparison of } \\
\text { Symptoms at } \\
\text { Pre and Post }\end{array}$ & Comparison of Conditions \\
\hline & & & & & $\begin{array}{l}\text { 48-hour } \\
\text { delayed } \\
\text { EMDR-RE } \\
N=18\end{array}$ & $\begin{array}{l}\text { Significant } \\
\text { decrease }\end{array}$ & $\begin{array}{l}\text { EMDR-RE =Delayed EMDR } \\
\text { REDelayed EMDR-RE }>\text { CISD }\end{array}$ \\
\hline \multirow[t]{2}{*}{ R-TEP } & $\begin{array}{l}\text { E. Shapiro, } \\
\text { Laub, and } \\
\text { Rosenblat }\end{array}$ & $\begin{array}{l}\text { Within } 3 \\
\text { months }\end{array}$ & $\begin{array}{l}\text { Intense } \\
\text { rocket } \\
\text { attacks }\end{array}$ & $\begin{array}{l}\text { Three } \\
\text { sessions } \\
90 \mathrm{~m}\end{array}$ & $\begin{array}{l}\text { Immediate } \\
N=13\end{array}$ & $\begin{array}{l}\text { Significant } \\
\text { decrease }\end{array}$ & Immediate $>1$ month waiting \\
\hline & $(2018)$ & & & & $\begin{array}{l}1 \text { month } \\
\text { Wait } \\
N=12\end{array}$ & No change & \\
\hline \multirow[t]{3}{*}{ R-TEP } & $\begin{array}{l}\text { Gil-Jardiné } \\
\text { et al. (2018) }\end{array}$ & $\begin{array}{l}\text { Within } \\
24 \text { hours }\end{array}$ & $\begin{array}{l}\text { Physical } \\
\text { injury or } \\
\text { acute }\end{array}$ & $\begin{array}{l}\text { One } \\
\text { session } \\
60 \mathrm{~m}\end{array}$ & $\begin{array}{l}\text { R-TEP } \\
N=42\end{array}$ & & $\begin{array}{l}\text { At } 3 \text { months } \\
\text { For PCLS: } \\
\text { R-TEP = Reassurance } \\
\text { R-TEP > TAU } \\
\text { Reassurance > TAU } \\
\text { For PTSD diagnosis: } \\
\text { R-TEP=reassurance=TAU }\end{array}$ \\
\hline & & & $\begin{array}{l}\text { medical } \\
\text { crisis, at risk } \\
\text { for PCLS }\end{array}$ & & $\begin{array}{l}\text { Reassurance } \\
N=47\end{array}$ & & \\
\hline & & & & & $\begin{array}{l}\text { TAU, } \\
N=41\end{array}$ & & \\
\hline
\end{tabular}

Note. $\mathrm{m}=$ minutes; PCLS = post-concussion-like symptoms; PROPARA = protocol for paraprofessional use; PTSD = posttraumatic stress disorder; R-TEP = recent traumatic episode protocol; TAU $=$ treatment as usual. by the RECI $=$ protocol for recent critical incidents EMDR-RE = recent traumatic event protocol

" $>$ " is significantly superior re symptom improvement and " $=$ " is no significant difference between conditions.

EMDR Protocol for Recent Critical Incidents. The EMDR protocol for recent critical incidents (EMDRPRECI; Jarero et al., 2011) is similar to F. Shapiro's REP, except that it addresses the extended continuum of events. No assessment or installation of positive cognitions are done until the entire continuum of events is completely processed. The individual protocol for paraprofessional use (PROPARA; Jarero et al., 2013) is a modified version of PRECI, in which the butterfly hug (Artigas et al., 2014) replaces eye movements. Evidence for PRECI (and PROPARA) as an early intervention is found in one controlled study (Jarero \& Uribe, 2011, 2012) and three RCTs (Jarero et al., 2011; Jarero et al., 2013; Jarero et al., 2015). See Table 2.

Recent Traumatic Episode Protocol. The recent traumatic episode protocol (R-TEP; E. Shapiro \& Laub, 2008) focuses on the entire episode from the onset event up to the present. The identification of the target fragments is done with a nonsequential metaphorical "google search/scan." As each point of disturbance is identified, it becomes the target for assessment and processing, using EMDR's standard eight phases, except that phase four desensitization is conducted using focused processing containment strategies for the associations, encouraging a current trauma episode focus. Evidence for R-TEP as an early intervention is found in three RCTs (Gil-Jardiné et al., 2018; E. Shapiro \& Laub, 2015; E. Shapiro et al., 2018). See Table 2.

\section{The Research Evidence for EMDR Early Intervention}

This article examines all seven randomized controlled studies which investigated EMDR early interventions. See Table 2. All provided individual 
treatment sessions. Participants were adults from varied traumatized populations: first responders (Jarero et al., 2013); victims of workplace violence/accidents (Tarquinio et al., 2016); patients in an emergency department (Gil-Jardiné et al., 2018); civilian survivors of a fatal rocket attack (E. Shapiro \& Laub, 2015) and victims of intense rocket attacks (E. Shapiro et al., 2018); a devastating earthquake (Jarero et al., 2011); and a fatal explosion (Jarero et al., 2015). These studies were conducted in France, Israel, and Mexico. The amount of treatment varied from one 60-minute session (Gil-Jardiné et al., 2018) to three sessions (E. Shapiro et al., 2018).

Although all studies provided treatment within 3 months of the event, the length of time between event and intervention varied across studies. Four RCTs provided EMDR early intervention during the first month: within hours (Gil-Jardiné et al., 2018); within 2 and 4 days (Tarquinio et al, 2016); at 15 and 24 days (Jarero et al., 2011); and at 25 and 34 days (Jarero et al., 2015). Three RCTs provided it between 2 and 3 months posttrauma: 42 and 49 days (E. Shapiro $\&$ Laub, 2015), 75 and 105 days (E. Shapiro et al., 2018), and within 3 months (Jarero et al., 2013).

Five studies used a waitlist comparison and reported that at posttest EMDR early intervention produced significant decreases in posttraumatic symptoms compared to wait list. Three studies compared the EMDR treatment to another intervention. Tarquinio et al. (2016) found that EMDR treatment was superior to critical incident stress debriefing in reducing posttraumatic symptoms. In the GilJardiné et al. (2018) study, there were no statistical differences between EMDR and reassurance treatment for post-concussion-like symptoms (PCLS) or PTSD self-reports. Jarero et al. (2013) reported that EMDR produced significantly greater reduction in PTSD symptoms compared to supportive counseling.

In all studies, there were significant decreases in symptoms of PTSD from pre- to posttreatment, with results maintained at follow-up (where this was assessed). Two studies (E. Shapiro \& Laub, 2015; E. Shapiro et al., 2018) also evaluated symptoms of depression, with results showing significant improvement. E. Shapiro et al. also assessed resilience, but the four-item measure they utilized showed only mixed results. They suggested seeking more sensitive measures for resilience in future research. Although none of the seven studies reported deleterious effects and it appears that all treatments were safe and well tolerated, safety was not directly assessed. To date, no study has directly shown that EMDR early intervention prevents PTSD or any other disorder, as clinically diagnosed. Neither does the research yet show that EMDR early intervention increases resilience. It is also observed that no RCT has examined the effectiveness of EMDR early interventions with children and adolescents.

A unique RCT was conducted in the emergency room by Gil-Jardiné et al. (2018). It treated patients who had been assessed at high risk of developing PCLS, which commonly develop in about $10 \%-20 \%$ of emergency room patients. Patients who received R-TEP or a reassurance treatment were significantly less likely to develop PCLS than those who received a no-treatment control, with respective rates of PCLS of $18 \%, 37 \%$, and $65 \%$ at 3 -month post-treatment. The development of PTSD was also assessed in this study, with self-report rates at 3 months of 3\% (R-TEP), $16 \%$ (reassurance), and 19\% (no treatment), although results were not statistically significant.

\section{Treatment Guidelines for Early Intervention}

\section{Guidelines for Children and Adolescents}

EMDR early intervention is not recommended in any guideline for children and adolescents, because there are no RCTs providing EMDR treatment within 3 months of the traumatic event for children and adolescents. However, EMDR therapy is recommended in the guidelines (with some conditions) for children and adolescents for treatment of PTSD. See Barron, Bourgaize, Lempertz, Swinden, and Darker-Smith (2019), De Jongh, Amann, Hofmann, Farrell, aand Lee (2019), and Dominguez and Lee (2019) for discussion of EMDR treatment of children and adolescents with PTSD in this issue.

\section{The 2013 WHO Guidelines for Adults}

At the time of the WHO analysis, there was only one EMDR RCT with adult participants (Jarero et al., 2011), which had provided treatment within the first month post-trauma and EMDR was assessed as lacking sufficient evidence. Only trauma-focused cognitive behavioral therapy (TF-CBT) was recommended for treatment within the first month. See Table 1. After the first month, for adults with PTSD, the WHO committee gave standard recommendations for individual 
or group TF-CBT, EMDR, and stress management, noting that the quality of evidence for CBT and EMDR was "moderate."

\section{The 2018 NICE Guidelines for Adults}

The NICE guidelines (2018) for PTSD addressed two main categories of adult intervention-prevention (for the first month post-trauma, and for those with subclinical symptoms) and treatment (early treatment during months 2 and 3, and delayed treatment after 3 months). In this article, we discuss prevention and early treatment (within months 2 and 3). The NICE PTSD guideline analysis of EMDR delayed treatment is discussed in two articles in this issue by Dominguez and Lee, and De Jongh, Amann et al.

NICE defined prevention as interventions provided to at-risk adults, with a diagnosis of acute stress disorder/acute stress reaction, or clinically important PTSD symptoms (within 1 month of the traumatic event) or with subthreshold symptoms. In evaluating EMDR prevention, the NICE committee included only two studies in their analyses: Gil-Jardiné et al. (2018) for prevention within the first month, and Lytle, Hazlett-Stevens, and Borkovec (2002) for standard EMDR treatment of those with subclinical symptoms. At least three EMDR RCTs that provided intervention in the first month for clinically important PTSD symptoms were overlooked or excluded by NICE: Tarquinio et al. (2016), Jarero et al. (2011), and Jarero et al. (2015). In their summary recommendation, the NICE guidelines did not recommend EMDR for adults within 1 month of the traumatic event or for adults with subclinical symptoms after 1 month. The guidelines recommended cognitive processing therapy, cognitive therapy for PTSD, narrative exposure therapy, and prolonged exposure therapy (NICE, 2018). See Table 1.

In the early treatment domain, the NICE committee identified only one RCT (Jarero et al., 2013) providing EMDR treatment within 2-3 months posttrauma. The E. Shapiro and Laub (2015) study was excluded because of small sample size. Jarero et al. (2015) and E. Shapiro et al. (2018) studies were not mentioned and were omitted. Since there was only one EMDR early treatment study, the committee extrapolated "from the stronger evidence for EMDR more than 3 months after trauma," and recommended "considering EMDR between 1 and 3 months after a non-combat-related trauma ... if the person has a preference for EMDR" (NICE, 2018, 1.6.18). The NICE guidelines recommended cognitive processing therapy, cognitive therapy for PTSD, narrative exposure therapy, and prolonged exposure therapy. See Table 1.

\section{The 2018 ISTSS Guidelines}

The ISTSS (2018) Treatment Guidelines defined early psychological intervention as occurring within the first 3 months postevent, and they distinguished between single-session interventions and multiplesession interventions. For multiple-session early treatment interventions, provided within the first 3- month posttrauma, the guidelines gave standard recommendations to TF-CBT, cognitive therapy, and EMDR for the treatment of PTSD symptoms in adults (ISTSS, 2018, p. 16). In this category, the ISTSS (2018) guidelines considered four EMDR RCTs (Jarero et al., 2011; Jarero et al., 2015, E. Shapiro \& Laub, 2015; E. Shapiro et al., 2018). The Jarero et al. (2013) study appears to have been overlooked. See Table 1.

For single-session interventions, provided within 3-month post-event, the guidelines evaluated three EMDR studies (Gil-Jardine et al., 2018: Jarero et al., 2011; Tarquinio et al., 2016). They made no strong or standard recommendations for any single-session treatment, but single-session EMDR therapy and the Group 512 PM group program were the only treatments to be recognized as having "emerging evidence of efficacy for the prevention and treatment of PTSD symptoms in adults" (ISTSS, 2018, p. 15). See Table 1. (Note: Group $512 \mathrm{PM}$ is "based on debriefing but supplemented with cohesion training exercises" such as games requiring team cooperation [ISTSS, 2018, p. 22]).

\section{Comparison of the Guidelines}

EMDR early intervention is recommended in the ISTSS guidelines but poorly represented in the NICE treatment guideline (see Table 1). While the WHO guideline recommends it for PTSD treatment after 1month post-trauma, and the ISTSS gives it a standard recommendation for use in the first 3months posttrauma, NICE states that it should not be used in the first month, and should only be used during months 2 and 3 if requested by the patient. The differences in the guidelines appear to be a result of the varying definitions of "early intervention," the timing of the guidelines, and which studies were included in the guideline analyses.

Early intervention was seen by WHO as occurring within the first month posttrauma. NICE viewed "prevention" as occurring within the first month posttrauma, and "early treatment" as occurring within 
months 2 and 3. ISTSS defined "early psychosocial interventions" as occurring during the first 3 month posttrauma but differentiated between single- and multiple-session interventions. These narrow categories mean that the whole body of EMDR work was never evaluated in a single analysis, and that the full picture of EMDR's effectiveness during the first 3 months posttrauma was not assessed in any guideline.

At the time of the WHO (2013) guidelines, there was only one published RCT for EMDR early intervention (Jarero et al., 2011). There were, however, seven RCTs available during the 2018 evaluations conducted by NICE and ISTSS. The ISTSS guidelines included six studies, and omitted the Jarero et al. (2013) study, which was not mentioned and apparently overlooked. However, the NICE (2018) guidelines included only two studies and omitted five. They excluded one study (E. Shapiro \& Laub, 2015) because of small sample size (less than 10 participants per arm), one study was published after their analysis (E. Shapiro et al., 2018), and three were not mentioned (Jarero et al., 2011; Jarero et al., 2015, Tarquinio et al., 2016). It is unclear whether the inclusion of these studies would have increased the confidence of the NICE committee in EMDR early intervention. Nevertheless, the exclusion of these studies indicates that NICE did not have all the information needed to adequately assess EMDR early interventions. The only guideline that included most of the EMDR early intervention RCTs was ISTSS (2018), and that committee gave EMDR a standard recommendation for adults during the first 3 months. This recommendation seems to the most fully informed, having evaluated the largest number of available studies, and therefore the most reliable.

\section{Discussion}

Seven RCTs have investigated the efficacy of EMDR early interventions. All reported significant decreases in PTSD symptoms, and those with follow-up assessments (3-6 month) showed that effects were maintained. These results appear to be robust and consistent, with similar outcomes across all studies. However, although the substantial variation in population, type of trauma, type of treatment, and number of sessions suggest that the results can be widely generalized, it also increases heterogeneity, which can reduce overall confidence.

It is also important to note that all controlled EMDR research in the first 3 months posttrauma has been conducted with adults. There is not one RCT investigating EMDR early interventions with children and adolescents. There is also not one RCT investigating EMDR group treatment within the 3-month posttrauma time frame.

\section{Recommendations for Clinicians}

There are major differences between the recommendations made in the ISTSS and NICE guidelines. It is apparent that the ISTSS guideline was more comprehensive and more inclusive, including three studies in the single session analysis and four studies in the multi-session analysis. Its standard recommendation for EMDR multi-session treatment, during the first 3 months posttrauma, was based on four EMDR studies. NICE included only one EMDR study in each of two analyses (prevention in the first month, and early treatment in months 2 and 3). The ISTSS guideline therefore should be considered more reliable, and clinicians should feel confident in relying on the ISTSS's directions.

The research for EMDR early intervention has been conducted using three individual treatment protocols: F. Shapiro's Recent Event Protocol (1995), E. Shapiro and Laub's R-TEP (2008), and Jarero et al.'s EMDR-PRECI (2011). These protocols share similarities but differ in various ways. It is not possible to know if they differ in effectiveness, as there has been no direct comparison of the treatments, and the research supporting each treatment was conducted with different populations. Clinicians may want to examine the protocols to determine if one is a better fit for their own personal use.

Clinicians should be aware of the limitations in the existing research base. There is no evidence that individual EMDR early intervention is effective for children or adolescents, and there is only one case study showing EMDR early intervention to be effective for one individual with combat trauma (Wesson \& Gould, 2009). Therefore, therapists considering EMDR early intervention for these populations should be conservative, consider that this still an experimental application, and carefully monitor the client's response to treatment.

Although there has been no RCT evaluating EMDR group treatment as an early intervention, there are at least nine case studies which showed the effectiveness of EMDR-IGTP (Artigas et al., 2014), primarily with children in disaster situations. Although these results are compelling, the study design does not control for other factors that may have caused the positive outcome, such as group interaction, therapist 
attention, and passage of time. Therefore, it cannot be concluded that EMDR-IGTP is efficacious. EMDRIGTP and G-TEP (E. Shapiro, 2012) have both been applied for treatment of ongoing stress beyond the 3month early intervention window, with preliminary evidence from RCTS showing them to be effective. In that regard, the provision of EMDR group treatment is an exciting development for clinicians, as it extends the availability of treatment to larger numbers of clients and in different contexts (e.g., community centers, clinics).

Some clinicians may want to wait to see if a recently traumatized client shows spontaneous recoverya common occurrence. However, EMDR clinicians should keep in mind that, according to the AIP model (F. Shapiro, 2018), unprocessed traumatic memories can be triggered at a later time, causing subsequent impairment and distress. The model predicts that successful processing of distressing memories should not only eliminate current symptoms, it should also prevent the development of debilitating psychological disorders such as PTSD and depression. There are also anecdotal reports of the development of resilience and growth (Rost, Hofmann, \& Wheeler, 2009; Sang Won et al., 2017; Smith-Lee Chong, 2015; Zaghrout-Hodali, Ferdoos, \& Dodgson, 2008). In addition, clinicians could consider the perspective of McFarlane (2009), who views PTSD as "part of a complex psychobiological process that leads to the emergence of the disorder in the weeks, months, or years after the event" (p. 85). He asserts that the sensitized psychobiological system is left vulnerable, especially to additional exposures, therefore risk remains even when there may only be subclinical symptoms, and he recommends early treatment. This view converges well with the AIP model that suggests early EMDR intervention may prevent the accumulation of unprocessed trauma memories.

\section{Recommendations for Researchers}

Even though there are now seven RCTs showing support for EMDR early intervention, there are still substantive gaps in the evidence base for EMDR early interventions. For example, in the ISTSS analysis of the four wait-list comparison studies, standard mean differences ranged from $0.74(1.57, .09)$ to 4.89 (6.56, 3.22). The test for overall effect was significant, $Z=$ 2.80, $p=.005$, but, there was also significant heterogeneity $\mathrm{I}^{2}=88 \%$, and the committee identified high risk of bias in these studies. Although the mean effect size was large enough to be classified as "clinically important," the committee assessed the quality of evidence as "very uncertain about the estimate." It is recommended that future trials adhere to the highest standards for clinical research, following established methodological guidelines such as those of the Consort 2010 guidelines for randomized research (http://www.consort-statement.org/).

It is imperative that researchers focus on evaluating EMDR's efficacy in the treatment of recent trauma to prevent PTSD and to reduce/eliminate PTSD symptoms. In order to investigate whether EMDR early intervention prevents PTSD, RCTs must evaluate whether participants are subsequently diagnosed with PTSD. To achieve this, researchers should conduct diagnostic assessments at posttreatment and follow-up, with clinician administered measurements, comparing the status of those who received EMDR treatment and those who had no treatment or a comparison treatment. In addition, it is recommended that research using participants with subclinical symptoms or ongoing trauma use measures that will assess the possible beneficial effect of treatment, such as quality of life, health inventories, missed days of employment, and number of medical appointments. It is also essential that some RCTs be conducted with children and adolescents, and that RCTs be conducted to evaluate group therapy as an early intervention.

\section{References}

Acarturk, C., Konuk, E., Cetinkaya, M., Senay, I., Sijbrandij, M., Gulen, B., \& Cuijpers, P. (2016). The efficacy of eye movement desensitization and reprocessing for post-traumatic stress disorder and depression among Syrian refugees: Results of a randomized controlled trial. Psychological Medicine, 46(12), 2583-2593. doi:10.1017/S0033291716001070

Artigas, L., Jarero, I., Alcalá, N., \& López Cano, T. (2014). The EMDR integrative group treatment protocol (IGTP) for children. In M. Luber (Ed.), Implementing EMDR early interventions for man-made and natural disasters (pp. 237-251). New York, NY: Springer Publishing.

Barron, I.G., Bourgaize, C., Lempertz, D., Swinden, C., \& Darker-Smith, S. (2019). Eye movement desensitization reprocessing (EMDR) for children and adolescents with posttraumatic stress disorder: A systematic narrative review. Journal of EMDR Practice and Research, 13(4), 270-283. doi:10.1891/1933-3196.13.4.270

Bryant, R. A., Creamer, M., O’Donnell, M., Silove, D., \& McFarlane, A. C. (2011). The capacity of acute stress disorder to predict posttraumatic psychiatric disorders. Journal of Psychiatric Research, 46(2), 168-173. doi:10.1016/j.jpsychires.2011.10.007

De Jongh, A., Amann, B. L., Hofmann, A., Farrell, D., \& Lee, C. W. (2019). The status of EMDR therapy in the treatment of posttraumatic stress disorder 30 years after its introduction. Journal of EMDR Practice and Research, 13(4), 261-269. doi:10.1891/ 1933-3196.13.4.261 
Dominguez, S., \& Lee, C. W. (2019). Differences in international guidelines regarding EMDR for PTSD: Why they diverge and suggestions for future research. Journal of EMDR Practice and Research, 13(4), 247-260. doi:10.1891/1933-3196.13.4.247

Faretta, E., Borsato, T., Civilotti, C., Fernandez, I., \& Pagani, M. (2016). EMDR and CBT: A comparative clinical study with oncological patients. Journal of EMDR Practice and Research, 10(3), 215-227. doi:10.1891/19333196.10.3.215

Gil-Jardiné, C. B., Evrard, G. B., Al Joboory, S., Tortes Saint Jammes, F. J., Masson, F., Régis Ribéreau-Gayon, C., . . . Lagarde, E. (2018). Emergency room intervention to prevent post concussion-like symptoms and post-traumatic stress disorder. A pilot randomized controlled study of a brief eye movement desensitization and reprocessing intervention versus reassurance or usual care. Journal of Psychiatric Research, 103, 229-236. doi:10.1016/j.jpsychires.2018.05.024

Hurley, E. C. (2018). Effective treatment of veterans with PTSD: Comparison between intensive daily and weekly EMDR approaches. Frontiers in Psychology, 9, 1458. doi:10.3389/fpsyg.2018.01458

ISTSS Guidelines Committee. (2018). Posttraumatic stress disorder prevention and treatment guidelines methodology and recommendations. Oakbrook Terrace, IL: Author. Retrieved from http://www.istss.org/ treating-trauma/new-istss-prevention-and-treatmentguidelines.aspx.

Jarero, I., Amaya, C., Givaudan, M., \& Miranda, A. (2013). EMDR individual protocol for paraprofessional use: A randomized controlled trial with first responders. Journal of EMDR Practice and Research, 7(2), 55-64. doi:10.1891/1933-3196.7.2.55

Jarero, I., \& Artigas, L. (2018). AIP model-based acute trauma and ongoing traumatic stress theoretical conceptualization. Iberoamerican Journal of Psychotraumatology and Dissociation. Revista Iberoamericana de Psicotraumatología y Disociación, 10(1), 1-9. Retrieved from http: / / revibapst.com

Jarero, I., Artigas, L., \& Hartung, J. (2006). EMDR integrative treatment protocol: A post-disaster trauma intervention for children and adults. Traumatology, 12, 121-129. doi:10.1177/1534765606294561

Jarero, I., Artigas, L., \& Luber, M. (2011). The EMDR protocol for recent critical incidents: Application in a disaster mental health continuum of care context. Journal of EMDR Practice and Research, 5(3), 82-94. doi:10.1891/1933-3196.5.3.82

Jarero, I., Givaudan, M., \& Osorio, A. (2018). Randomized controlled trial on the provision of the EMDR integrated group treatment protocol adapted for ongoing traumatic stress to female patients with cancer-related PTSD symptoms. Journal of EMDR Practice and Research, 12(3), 94-104. doi:10.1891/1933-3196.12.3.94

Jarero, I., \& Uribe, S. (2011). The EMDR protocol for recent critical incidents: Brief report of an application in a human massacre situation. Journal of EMDR Practice and Research, 5(4), 156-165.

Jarero, I., \& Uribe, S. (2012). The EMDR protocol for recent critical incidents: Follow-up report of an application in a human massacre situation. Journal of EMDR Practice and Research, 6(2), 50-61. doi:10.1891/1933-3196.6.2.50

Jarero, I., Uribe, S., Artigas, M., \& Givaudan, M. (2015). EMDR protocol for recent critical incidents: A randomized controlled trial in a technological disaster context. Journal of EMDR Practice and Research, 9(4), 166-173. doi:10.1891/1933-3196.9.4.166

Kearns, M. C., Ressler, K. J., Zatzick, D., \& Rothbaum, B. O. (2012). Early intervention for PTSD: A review. Depression and Anxiety, 29(10), 833-842. doi:10.1002/da.21997

Lytle, R. A., Hazlett-Stevens, H., \& Borkovec, T. D. (2002). Efficacy of eye movement desensitization in the treatment of cognitive intrusions related to a past stressful event. Anxiety Disorders, 16, 273-288. doi:10.1016/S08876185(02)00099-3

Maxfield, L. (2018). Appendix E. Research on EMDR early intervention protocols. Retrieved from https:// emdrresearchfoundation.org/wp-content/uploads / 2019/04/toolkit-with-appendices. pdf, 70-72

McFarlane, A. C. (2009). The duration of deployment and sensitization to stress. Psychiatric Annals, 39(2), 81-88. doi:10.3928/00485713-20090201-05

McFarlane, A. C., Lawrence-Wood, E., Van Hooff, M., Malhi, G. S., \& Yehuda, R. (2017). The need to take a staging approach to the biological mechanisms of PTSD and its treatment. Current Psychiatry Reports, 19(2), 10. doi:10.1007/s11920-017-0761-2

Morina, N., Wicherts, J. M., Lobbrecht, J., \& Priebe, S. (2014). Remission from post-traumatic stress disorder in adults: A systematic review and meta-analysis of long term outcome studies. Clinical Psychology Review, 34(3), 249-255. PMID: 24681171. doi:10.1016/j.cpr.2014.03.002

National Institute for Health and Clinical Excellence. (2018). Post-traumatic stress disorder. Evidence reviews on care pathways for adults, children and young people with PTSD. Retrieved from https://www. nice.org.uk/guidance/ng116

Rost, C., Hofmann, A., \& Wheeler, K. (2009). EMDR treatment of workplace trauma: A case series. Journal of EMDR Practice and Research, 3(2), 80-90. doi:10.1891/1933-3196.3.2.80

Saltini, A., Rebecchi, D., Callerame, C., Fernandez, I., Bergonzini, E., \& Starace, F. (2017). Early eye movement desensitisation and reprocessing (EMDR) intervention in a disaster mental health care context. Psychology, Health \& Medicine , 1-10. doi:10.1080/13548506.2017 .1344255

Sang Won, J., Changsu, H., Joonho, C., Young-Hoon, K., Ho-Kyoung, Y., \& Yong-Ku, K. (2017). Eye movement desensitization and reprocessing to facilitate posttraumatic growth: A prospective clinical pilot study on ferry disaster survivors. Clinical Psychopharmacology and Neuroscience, 15(4), 320-327. doi:10.9758/cpn.2017.15.4.320 
Santiago, P. N., Ursano, R. J., Gray, C. L., Pynoos, R. S., Spiegel, D., Lewis-Fernandez, R., . . . Fullerton, C. S. (2013). A systematic review of PTSD prevalence and trajectories in DSM-5 defined trauma exposed populations: Intentional and non-intentional traumatic events. PLOS ONE, 8(4), e59236. doi:10.1371/journal.pone.0059236

Shalev, A. Y., Ankri, Y., Gilad, M., Israeli-Shalev, Y., Adessky, R., Qian, M., \& Freedman, S. (2016). Long-term outcome of early interventions to prevent posttraumatic stress disorder. The Journal of Clinical Psychiatry, 77(5), e580-e587. doi:10.4088/JCP.15m09932

Shapiro, E. (2012). EMDR and early psychological intervention following trauma. L'EMDR et l'intervention psychologique précoce à la suite d'un traumatisme. European Review of Applied Psychology (Revue européenne de psychologie appliquée), 62, 241-251. doi:10.1016/j.erap.2012.09.003

Shapiro, E. (2014, June). Recent simplified individual and group applications of the EMDR R-TEP for emergency situations. Paper session presented at the annual meeting of EMDR Europe, Edinburgh.

Shapiro, E., \& Laub, B. (2008). Early EMDR intervention (EEI): A summary, a theoretical model, and the recent traumatic episode protocol (R-TEP). Journal of EMDR Practice and Research, 2(2), 79-96. doi:10.1891/19333196.2.2.79

Shapiro, E., Laub, B., \& Rosenblat, O. (2018). Early EMDR intervention following rocket attacks on a town: A randomised clinical trial. Clinical Neuropsychiatry, 15(3), 112123. doi:10.1037/t06165-000

Shapiro, E., \& Laub, B. (2015). Early EMDR intervention following a community critical incident: A randomized clinical trial. Journal of EMDR Practice and Research, 9(1), 17-27. doi:10.1891/1933-3196.9.1.17

Shapiro, F. (1995). Eye movement desensitization and reprocessing: Basic principles, protocols, and procedures. New York, NY: Guilford.

Shapiro, F. (2018). Eye movement desensitization and reprocessing: Basic principles, protocols, and procedures (3rd ed.). New York, NY: Guilford.

Smith-Lee Chong, P. A. (2015). The experiences of EMDR therapists when working with PTSD. Doctoral thesis, Wolverhampton Intellectual Repository and E-Theses, Wolverhampton University, UK.
Tarquinio, C., Rotonda, C., Houllé, W. A., Montel, S., Rydberg, J. A., \& Minary, L. (2016). Early psychological preventive intervention for workplace violence: A randomized controlled explorative and comparative study between EMDR-recent event and critical incident stress debriefing. Issues in Mental Health Nursing, 37(11), 787799. doi:10.1080/01612840.2016.1224282

Utzon-Frank, N., Breinegaard, N., Bertelsen, M., Borritz, B., $\&$ Hurwitz Eller, N. (2014). Occurrence of delayed-onset post-traumatic stress disorder: A systematic review and meta-analysis of prospective studies. Scandinavian Journal of Work, Environment \& Health, 40(3), 215-229. PMID: 24599261. doi:10.5271/sjweh.3420

Wesson, M., \& Gould, M. (2009). Intervening early with EMDR on military operations: A case study. Journal of EMDR Practice and Research, 3(2), 91-97. doi:10.1891/1933-3196.3.2.91

World Health Organization. (2013). Guidelines for the management of conditions that are specifically related to stress. Geneva: Author.

Yehuda, R., Hoge, C. W., McFarlane, A., Vermetten, E., Lanius, R. A., Nievergelt, C. M., .. Hyman, S. E. (2015). Post-traumatic stress disorder. Nature Reviews Disease Primers, 1, 15057. doi:10.1038/nrdp.2015.57

Yurtsever, A., Konuk, E., Akyüz, T., Tükel, F., Zat, Z., \& Çetinkaya, M. (2018). An eye movement desensitization and reprocessing (EMDR) group intervention for syrian refugees with post traumatic stress symptoms: Results of a randomized controlled trial. Frontiers in Psychology, 9, 1-8. doi:10.3389/ fpsyg.2018.00493

Zaghrout-Hodali, M., Ferdoos, A., \& Dodgson, P. W. (2008). Building resilience and dismantling fear: EMDR group protocol with children in an area of ongoing trauma. Journal of EMDR Practice and Research, 2(2), 106113. doi:10.1891/1933-3196.2.2.106

Disclosure. E.S. receives fees from training therapists to use R-TEP and G-TEP. L.M. receives income from a published book on EMDR therapy and is the editor-in-chief of this journal.

Correspondence regarding this article should be directed to Elan Shapiro, Ramat Yishay, Israel. E-mail: elanshapiro (a)gmail.com 